\title{
Revisando algunos aspectos de nuestra salud mental
}

\author{
Reviewing some aspects of our mental health

\section{Luis Cibanal Juan} \\ Catedrático de Escuela Universitaria de Enfermería, especialidad en Enfermería Psiquiátrica. Universidad de Alicante, España. \\ Contacto: luis.cibanal46@gmail.com \\ Fecha de recepción: 7 de marzo de 2020 / Fecha de aceptación: 11 de marzo de 2020
}

\begin{abstract}
Resumen
Se sigue mezclando salud mental y enfermedad mental. De la misma manera que todos tenemos a lo largo de nuestra vida ciertos problemas físicos, que no enfermedades físicas (aunque también), también tenemos ciertos problemas psicológicos o mentales sin que por eso sean enfermedades mentales. Uno de los pilares fundamentales de una buena salud mental es la autoestima. Como punto de partida, la visión que nos da sor Callista Roy de la imagen que uno tiene de sí mismo. También se recorrerán las bases de la autoestima, de su cuidado y las consecuencias de tener una autoestima adecuada o baja.
\end{abstract}

Palabras clave: salud mental, autoimagen, autoestima.

\begin{abstract}
The mixture of mental health and mental disorders persists. Just as, along our lives, we all have certain physical problems (not necessarily physical illnesses), we also have certain mental or psychological problems, different from mental disorders. One of the main pillars of good mental health is the Self-esteem. As a starting point, Sister Callista Roy's description of the own image of the self. Other aspects discussed will be the self-esteem basics, its care and the consequences of having an appropriate or a low self-esteem.
\end{abstract}

Keywords: mental health, self concept, self esteem.

Al leer trabajos de fin de máster de algunos alumnos, observo cómo se sigue mezclando salud mental y enfermedad mental. Esta mezcla, a mi parecer, lleva a los profesionales de enfermería no especialistas en salud mental y psiquiatría a pensar y, sobre todo, confundir a las personas que, debido a problemas de ansiedad, estrés, depresión, baja autoestima, etc., envíen a algunos pacientes a salud mental. Estos pacientes reaccionarán de forma negativa, diciéndoles que ellos no están locos. Debido a esta confusión, no es de extrañar que llamen a los psicólogos loqueros y, por tanto, que vean con malos ojos que uno vaya al psicólogo, cuando sabemos que en ciertas circunstancias un buen asesoramiento de lo que es y no es la salud mental les ayudaría enormemente. Una cosa es la salud y otra la enfermedad y todos sabemos por experiencia que, de la misma manera que todos tenemos a lo largo de nuestra vida ciertos problemas físicos, que no enfermedades físicas (aunque también), también tenemos ciertos problemas psicológicos o mentales sin que por eso sean enfermedades mentales.
Pues bien, entre los muchos aspectos a considerar sobre cómo tener una buena salud mental y así mismo prevenir que ciertos problemas psicológicos lleguen a ser una enfermedad mental, me voy a parar en un aspecto que desde mi punto de vista es uno de los pilares fundamentales de una buena salud mental, se trata de la estima del yo o autoestima.

Para ello voy a tomar como punto de partida la visión que nos da sor Callista Roy en su modelo, si bien yo lo he adaptado o explicado de forma más acomodada a nuestra comprensión y cultura. Roy nos habla entre otros aspectos de la:

Imagen que uno tiene de sí mismo: Esta imagen la divide en yo físico y yo íntimo.

Entendemos por imagen de sí (o concepto de sí mismo) al conjunto de creencias y sentimientos que el individuo tiene de él mismo en un momento dado, se compone de sus percepciones internas y de las percepciones que tiene de los otros o de sus reacciones y que influencian su comportamiento. 
Esta imagen la podemos dividir en dos partes: la imagen física o yo físico, y la imagen íntima o yo más psicológico. Ambas son muy importantes en nuestra vida por sus repercusiones a nivel de salud fisica y sobre todo mental.

\section{Yo físico}

Es la evaluación que el individuo hace de su ser físico incluyendo sus atributos físicos, su funcionamiento biológico, su sexualidad, su estado de salud o de enfermedad y su apariencia. Nuestro yo físico lo podemos ver desde dos perspectivas:

A) Sensaciones corporales: Cómo el individuo se siente en su cuerpo, qué sensaciones le envía el cuerpo y en qué medida las escucha. Todos sabemos, por ejemplo, cómo el dolor es un mecanismo, una llamada de atención, sumamente importante, que tiene nuestro organismo para manifestarnos que algo no va bien o como debiera funcionar.

Si el dolor es una alarma tan importante, cabe preguntarnos el por qué no lo escuchamos; por qué no nos paramos a ver qué significa este dolor en nuestra vida, qué me está diciendo este dolor. Pues es evidente que si ante el dolor, en vez de escucharlo, lo "apagamos" con un medicamento, de momento se va, pero no se ha resuelto la causa del mismo o su origen. De aquí que no es de extrañar que más tarde aparezcan problemas de salud serios; sin embargo, el cuerpo con su manifestación de dolor nos los iba indicando. Pero claro, es más fácil utilizar un medicamento, que pararnos y cambiar hábitos físicos o psíquicos que son los causantes de ese dolor.

El dolor es una de las manifestaciones, pero también hay otras sensaciones que permiten al individuo ver la experiencia de su cuerpo. Por ejemplo: me siento fatigado, enfermo, con malestar, tengo hambre, frío, calor, etc. Todas estas sensaciones físicas van a tener también una respuesta psicológica, y así la persona que tiene hambre, o frío o calor... lo va a manifestar con cierto malestar que se puede traducir en irritación, ansiedad, agresividad, susceptibilidad, etc. Estas manifestaciones pueden ser verbales, pero también en muchas otras situaciones pueden ser no verbales, que se manifiestan en la expresión facial, en tensiones musculares, etc.

B) Imagen corporal (Esquema corporal): Es decir, cómo el individuo percibe su cuerpo, sus rasgos corporales. Se trata de la percepción y los sentimientos que experimenta el individuo frente a la imagen de su cuerpo. Aquí nos paramos a tomar conciencia de cómo la persona percibe su cuerpo físico. Por ejemplo, cómo se siente frente a su apariencia personal: yo soy grande, pequeño, guapo, feo, obeso, delgado, etc.

De todos es conocido cómo hoy día damos muchísima importancia a nuestro cuerpo físico: como testimonio de esto, ahí están las dietas, las cremas, las operaciones dermoestéticas... Nuestro cuerpo, en el mejor de los casos, poco a poco va envejeciendo, y nos cuesta aceptarlo; sin embargo, hay situaciones límites como una enfermedad degenerativa, un accidente en el que la persona se puede quedar hemipléjico o tetrapléjico, una intervención quirúrgica, etc. Estas situaciones implican un trabajo profundo sobre la persona para aceptar su nueva imagen, lo cual lleva anejo el que tiene que ir haciendo (si va envejeciendo) o hacer (caso de enfermedad, accidente, operación) un duelo, o varios duelos ante el cuerpo que era y que ya no es o no lo será nunca.

Como vemos aquí hay mucho que trabajar a nivel de la autoestima que se va a sentir lastimada, y que se puede traducir en sentimientos de miedo, ansiedad, culpa, agresividad, angustia, depresión, suicidio, etc.; todo un campo amplio relacionado con nuestra salud mental.

\section{Yo íntimo o yo psicológico}

Es la evaluación que el individuo hace de sus propias características psicológicas, de su autoestima de lo que espera de la vida, de sus valores y de su mérito personal. Para una mejor comprensión de la importancia de esta parte, vamos a dividirlo en varios apartados:

A) Consistencia del yo: Llamamos consistencia del yo, como su nombre lo indica, a la parte que hace referencia a la estructura o cimientos de nuestra personalidad. Una estructura, unos cimientos poco sólidos hacen que la persona viva con ansiedad, con angustia, pues en cualquier momento se puede desmoronar el "edificio de su personalidad".

Se trata de ver cómo el individuo se percibe en relación con su performance o su respuesta a los diversos problemas, vivencias, situaciones que se dan en la situación actual. Por ejemplo: describirse como persona. Describir las características personales. Yo soy una persona débil, fuerte, voluntaria, tímida, incapaz, infantil, sin valor. 
Lógicamente, una persona que tiene buenos cimientos (buena autoestima) se siente segura, afronta la vida sin miedo, sin ansiedad. Toda situación nueva la ve como un reto, para seguir avanzando y creciendo. Y, por el contrario: todo lo que amenaza la consistencia del yo, o lo que es lo mismo los pilares sobre los que está construida nuestra persona nos provoca más o menos ansiedad, la cual se canalizará en las diversas psicopatologías o en las enfermedades psiquiátricas que todos conocemos.

B) Ideal del yo: Lo que el individuo querría llegar a ser o a hacer con relación a sus capacidades y objetivos.

Otro punto muy importante que tenemos que valorar son las metas u objetivos que tenemos o nos proponemos en nuestra vida. Es decir, qué aspiraciones o, en cierto modo, ilusiones tenemos en la vida.

Necesitamos tener objetivos o metas en nuestra vida, unos serán más a largo plazo, otros a corto o medio plazo. La falta de objetivos nos lleva al vacío existencial, a no encontrar sentido a la vida. Nuestra vida tiene sentido, porque continuamente se lo estamos dando programándonos cosas o vivencias que nos ilusionan o nos llenan. El sentido de la vida es algo que cada uno va buscando y va encontrando, por tanto es muy personal, nadie nos puede dar el sentido de la vida.

Es importante que nuestras metas u objetivos de vida estén programados de tal manera que podamos conseguirlos, pues de lo contrario nos sentiríamos fracasados, hundidos y deprimidos, de aquí que:

Debemos distinguir entre mi yo ideal: lo que me gustaría ser pero que o bien no tengo capacidades (físicas o intelectuales) o bien, aunque tenga capacidades, no dispongo de los recursos económicos o los medios para poder realizar mis objetivos, como, por ejemplo, poder hacer una carrera, $y$ resulta que económicamente no dispongo de un mínimo de dinero para pagarme los estudios. Por tanto, proponernos un yo ideal, o idealista que está fuera de nuestro alcance o realidad, nos llevaría al fracaso y hundimiento, pues nunca lo podríamos conseguir.

Mi yo real se refiere a todo lo que actualmente tengo, y esto tanto a nivel físico como intelectual, así como de medios, bien sean económicos u otros... Sin embargo, en vez de seguir avanzando y realizando aquellas aspiraciones que me gustaría alcanzar, y para las que tengo posibilidades, me estanco, bien sea por pereza, cansancio, tener que trabajar, etc. Lógicamente, quedarnos en este yo real y no seguir avanzando hasta todo lo que puedo llegar a ser me va a crear frustración, culpabilidad, sensación de fracaso. Como algo que podía haber sido (pues tenía todas las posibilidades) y no ha sido, por no haberme planificado y hecho frente a las diversas dificultades.

Mi yo autentico lo que tengo más todo lo que puedo llegar a ser si desarrollo mis capacidades. Como vemos, este es el más equilibrado, pues sigo continuamente desarrollando mis capacidades y poniéndome metas y objetivos que están a mi alcance y que, por tanto, poco a poco, puedo llegar a conseguir. Podíamos decir que este es el hombre autorrealizado.

Y ahora vamos a abordar el tema fuerte de este artículo: la autoestima.

C) La estima del yo o la autoestima: Aspecto del yo personal relacionado con el valor que la persona se atribuye. Desde nuestro punto de vista, es la piedra angular sobre la que se edifica toda nuestra personalidad. Se vive la autoestima como un sentimiento que a veces puede ser difícil de aislar o identificar porque se experimenta constantemente. La estima de sí forma parte de cada sentimiento y de cada respuesta emocional de la persona; se trata pues de un concepto significativo para el análisis de la imagen de sí y de su crecimiento personal.

Cada persona necesita tener valores positivos sobre su autoimagen, esto le ayudará a ser creativo, confiar más en él mismo, enfrentarse positivamente ante su medio ambiente, etc.

A este respecto conviene recordar que la calidad y la cantidad de refuerzos positivos (caricias, diría el Análisis Transaccional) que recibe la persona a lo largo de su vida son cruciales, pues estos son la base de la evaluación de sí mismo y, por tanto, de su crecimiento como persona.Veamos algunas ideas generales sobre la autoestima:

Definición de la autoestima. Entre otros aspectos, podríamos definirla como:

- Soy una persona capazy valiosa.

- Soy una persona digna de confianza y respeto: por uno y por los otros.

- Soy digno de ser amado y de amar.

- Tengo recursos y habilidades. 
- Tengo alegría de vivir.

- Trato de tener continuamente pensamientos positivos.

- Autoestima es lo que pienso de mí, no lo que los otros piensan de mí.

Cómo y cuándo se crea o se fortalece la autoestima: En primer lugar, en el vientre materno: si consideramos a la persona como un edificio, y perdonad la comparación, sabemos que un edificio tantos más pisos podrá tener cuanto más sólidos sean sus cimientos. Desde mi punto de vista, nuestros cimientos son los nueve meses de vida intrauterina. Ahí ya se forja mucho de lo que después seremos. A modo de ejemplo, transcribo algunas ideas que van en la línea de la psicología transpersonal y también en un libro que les recomiendo a los profesionales para que lo aconsejen y recomienden leer a las futuras mamás. El libro lleva por título: $L a$ vida intrauterina del niño antes de nacer, del Dr. Thomas Verny (Ed. Urano, 1988). Dado el poco espacio del que disponemos, les pongo algunas ideas para su reflexión:

- El niño en el vientre de la madre es sensible a los matices emocionales: amor, odio, ansiedad, ambivalencia, ambigüedad, etc., que vive la madre.

- Nuestros gustos y aversiones, nuestros miedos y fobias... son parcialmente producto de lo que el niño ha ido recibiendo en el vientre materno. El útero es dónde se inicia este tipo de aprendizaje.

- La personalidad del niño intrauterino es una función de la calidad de comunicación madre-hijo y también de su especificidad.

- Si la comunicación con el feto durante los nueve meses fue abundante y enriquecedora y, sobre todo, nutritiva, existen muchas posibilidades de que el bebé sea sano, robusto y feliz.

- Es sumamente importante que la madre embarazada piense en su hijo (que cree con él un vínculo relacional). Los pensamientos y sentimientos de amor, rechazo, ambivalencia... de la madre hacia su bebé en gestación comienzan a definir y modelar la vida emocional del niño. Sobre todo, el sentimiento de seguridad y autoestima.

- Los niños no nacen tímidos, sino ansiosos y a partir de esa ansiedad puede surgir una temerosa timidez.

- Al crear en el útero un entorno cálido y emocionalmente enriquecedor, la mujer puede lograr una diferencia decisiva en todo lo que su hijo siente, espera, sueña, piensa y obtiene a lo largo de su vida.

- La mujer es el nexo entre su bebé y el mundo. Todo lo que le afecta a ella incide en él. No hay nada que la afecte más profundamente ni que la alcance con un impacto tan hiriente como las preocupaciones con respecto a su marido o compañero.

- Por este motivo, emocional y físicamente hay pocas cosas más peligrosas para un niño que un padre que maltrata o deja sola a su pareja embarazada.

- Freud demostró, más allá de toda duda, que las emociones y los sentimientos negativos influyen adversamente en la salud física. Dio a esta idea el nombre de enfermedades psicosomáticas.

- El amor es lo más importante y, cuando el niño lo percibe, a su alrededor se forma una especie de escudo protector que puede disminuir o, en algunos casos, neutralizar el impacto de las tensiones del exterior.

- En síntesis, aunque las tensiones externas que afronta una mujer embarazada tienen importancia, lo más esencial es lo que siente hacia su hijo no nacido.

- Sus pensamientos y sentimientos son el material a partir del cual el niño intrauterino se forja a sí mismo. Si son positivos y nutritivos, el niño puede soportar choques prácticamente de cualquier dirección.

- Los hijos de las madres aceptadoras son emocional y físicamente mucho más sanos al nacer, e incluso después, que los vástagos de las madres rechazadoras.

- En un estudio realizado con más de 1300 niños y sus familias, se observó que una mujer miembro de un matrimonio mal avenido corre un riesgo 237 veces superior de alumbrar un niño psicológica o físicamente enfermo más que una mujer que vive una relación segura y nutritiva.

- Asimismo, también se ha observado en algunas investigaciones que los matrimonios desdichados tenían hijos que, de pequeños, eran cinco veces más asustadizos que los vástagos de relaciones felices. También se muestran más tímidos y dependientes de la madre en grado excesivo. El útero es el primer mundo del niño. En un sentido muy real, el útero establece las expectativas del niño ante el mundo externo de amor, confianza... o de desconfianza, recelo, hostilidad, introversión...

Estas ideas novedosas han salido directamente de los laboratorios de Estados Unidos, Canadá, Inglaterra, Francia, Suecia, Alemania, Austria, Nueva Zelanda y Suiza, donde, durante las últimas dos décadas, los investigadores han trazado callada y concienzudamente una perspectiva espectacularmente nueva del feto, del nacimiento y de las primeras etapas de la vida. 
A este respecto, C. Rogers nos dirá: "Somos como una planta, una semilla..., que hay que comenzar a mimar desde que se planta”.

La mayor parte de los psicólogos que ha estudiado esto nos insisten en la importancia de favorecer la autoestima siempre, pero principalmente durante los primeros 4 años.

Cuando somos niños, los adultos (padres, abuelos, profesores...), según nos respeten, amen, valoren, así van a favorecer o destruir nuestra autoestima. Para ello es conveniente y necesario que tengan mucho cuidado con los mensajes que les dan, si son positivos, la favorecen y solidifican su personalidad, si son negativos, la destruyen. Nuestros padres, abuelos, profesores, etc., nos deben enseñar a:

- Tener confianza en nosotros y en los demás.

- A luchar contra el miedo al qué dirán y el "postureo", que tanto nos puede condicionar y amargar la vida al no valorarnos y querernos como somos y depender de lo que digan los demás.

- A querer y aceptar al niño/a por sí mismo, sin condicionantes.

- Alimentar la autoestima teniendo en cuenta las doce leyes sobre las caricias de las que nos habla el análisis transaccional, y que exponemos brevemente a continuación. Lo que llama caricias son como estímulos que van a favorecer el crecimiento y bienestar personal.

\section{Las doce leyes de las caricias}

\section{La caricia es indispensable para la supervivencia biológica y psicológica}

La experiencia en cuidados maternales pone de manifiesto que los "bebés acariciados" se desarrollan, en general, de manera más armoniosa que los carentes de tales caricias.

\section{La caricia puede ser fuente de energía positiva o negativa}

- La caricia positiva corresponde al reconocimiento de las cualidades del otro para valorarlas o de cualquier comportamiento o actividad que provocan en el otro el desarrollo de una energía positiva. Las caricias positivas me permiten vivir mejor conmigo mismo y con los demás.

- La caricia negativa corresponde a la desvaloriza- ción del otro, a no reconocer sus cualidades o a comportarse de tal manera que provocan en el otro energía negativa. Las caricias negativas me permiten vivir, sí, pero vivir sufriendo y sintiéndome mal “en mi piel" con una "especie" de ansiedad, en continuo malestar, vacío y relaciones difíciles con los demás.

\section{La persona prefiere una caricia negativa al riesgo de no recibir ninguna}

La ausencia de caricias es dramática para una persona. Es la causante de una disminución de energía, de falta de sentido de vida con cierta frecuencia son el presagio de una desaparición de sí mismo (enfermedad o muerte/suicidio). Sin embargo, las personas, por lo mismo, prefieren caricias negativas a la ausencia de las mismas, pues prefieren recibir maltratos a ser ignorados. Esto explica los numerosos comportamientos desagradables, provocadores o manifiestamente destinados a provocar fracasos o enfados en todo el mundo. Son, a pesar de todo, una dolorosa y trágica función de supervivir.

\section{La caricia puede ser condicional o incondicional}

- La caricia condicional es un signo de reconocimiento condicionado por el comportamiento del otro.

- La caricia incondicional no está relacionada directamente a los comportamientos de otra persona, ni propios; al contrario, consiste en apreciar la personalidad de cada uno con sus cualidades y sus defectos y no por lo que hace. Es querer, amar a la persona por ella misma, incondicionalmente.

La persona habituada a las caricias condicionales tiene necesidad de probar constantemente su valor comportándose de manera que le puedan dar caricias de recompensa.

\section{La caricia incondicional es más intensa que la con- dicional}

\section{La caricia incondicional positiva}

Debe tener estas cinco cualidades: sincera, apropiada, personalizada, dosificada y argumentada.

Recordemos: nunca dar caricias incondicionales negativas, son destructivas de nuestra autoestima. Por ejemplo, el niño hace una cosa mal y la madre o el padre... le dice: "Uf, qué tonto eres", "eres un desastre, todo lo que tocas lo estropeas", etc., en vez de decirle: 
"Cuando haces una cosa así, te comportas como un niño que no piensa"; esto es una caricia condicional negativa, que ayudan a cambiar y no destruyen a la persona como los mensajes: qué tonto eres, eres un desastre, etc., y que a veces se dicen por cosas de poca importancia, pero se quedan impresos en la persona y luego en su vida cuando no le sale alguna cosa bien, se dice: "No, si ya mi madre me decía que era un desastre, que todo lo que tocaba lo echaba a perder".

7. Para obtener la misma cantidad de energía psíquica, hace falta una caricia (+) por diez caricias (-)

Una persona deficiente en caricias positivas tiene la necesidad de multiplicar las ocasiones de caricias negativas para recibir la misma cantidad de energía para sobrevivir. De aquí que no nos debe de sorprender el que algunas personas vayan con mucha frecuencia provocando o de alguna manera llamando la atención de los demás.

8. Cada individuo tiene una "dosis" habitual de caricias y se resiente si las rebasa (como la temperatura del cuerpo)

Hacer cumplidos demasiado fuertes o poco habituales inquieta a la persona que los recibe. Buscar acariciar positivamente a los otros permite desarrollar su energía, si se hace respetando "la dosis habitual" de cada persona.

9. Cada persona tiene un canal preferencial de caricias

Existen cinco canales posibles de caricias:

- La mirada, los ojos, la vista.

- La voz, la palabra, la música, el sonido.

- La escritura, la nota, la memoria.

- La proximidad, el contacto, tocar.

- El olfato, el aroma, el olor.

Una buena observación de las personas nos permitirá tener en cuenta el canal o canales preferenciales de cada uno.

\section{Cada uno puede almacenar las caricias}

Es posible, en efecto, almacenar reserva de caricias durante ciertos momentos del día... para utilizarlos en los momentos en que faltan tales caricias.

\section{Cadapersona posee un "filtro" para las caricias}

Según su personalidad y los hábitos de su medio ambiente, cada persona tiene una disposición a aceptar o rehusar, total o parcialmente, las caricias que le dan. Por desgracia hay algunas personas que interpretan las caricias positivas como negativas.

Cada uno debe conocer hasta qué punto, según sea su autoestima, él rehúsa la caricia o la selecciona según su sistema psicológico personal.

El efecto de la caricia es esencial en la vida y por eso hay circunstancias en las que se tiene miedo y ha sido reglamentado. En la infancia, la familia “enseña” esos filtros como defensa personal. Esto corresponde a la "Ley de economía de caricias".

12. La caricia es una fuente natural, gratuita, inagotable y al alcance de todos

La caricia es una fuente natural que todos tenemos a nuestra disposición y así podemos dar, recibir y distribuir a todos y en toda ocasión.

Cada uno puede reconquistar este derecho a acariciar y permitir a los otros encontrar este bien, fuente de energía positiva para resolver los problemas de la vida.

\section{Pilares más importantes de la autoestima}

- Adquirir mayor conocimiento de uno mismo

- Saber aceptarse

- Ser confirmados por los otros como personas valiosas y dignas de ser amadas.

- Planificar cosas y realizarlas.

- Aceptarse como una persona valiosa, aceptar su cuerpo y darse mensajes positivos

- No criticarse.

La autoestima facilita:

- Las relaciones consigo mismo.

- Las relaciones familiares.

- Las relaciones de pareja.

- Las relaciones sociales.

- Las relaciones profesionales.

- Escoger y tener una profesión.

- La confianza en sus posibilidades y capacidades...

- Una buena autoestima facilita la aceptación de la realidad. 
- Se es más comprensivo, flexible, empático, se es más creativo.

- Se tiene más amor y más éxito.

\section{Labaja autoestima:}

- Hace que la persona se aísle más.

- Se sienta que vale poco;

- que no merece la pena que la quieran.

- Suele enfermar más por tener más una tendencia hacia lo negativo y el pesimismo.

- Sus relaciones son más conflictivas.

- Se tiene menos respeto por uno y por los demás.

- Se critica mucho y de forma despiadada.

- Suele tener más ansiedades y miedos.

- Suele tener más fracasos y más problemas.

- Se siente con frecuencia inútil, o que no vale, o que no es digno de ser querido.

Cómo aumentar la autoestima:

- Visualización y afirmaciones positivas.

- Valorarnos.

- Querernos.

- No criticarnos.

- Darnos muchos mensajes positivos (tú vales, lo vas a conseguir, las cosas me van a ir bien, hoy me siento feliz, yo puedo superar este bache).

- Cambiar nuestros pensamientos negativos en positivos sin perder el sentido de la realidad.

- No aceptando las críticas destructivas, ni los mensajes negativos de los otros.

- Expresando los sentimientos ya sean positivos pues redundan en amor hacia sí; ya sean los negativos para que no se transformen en enfermedad.

- Creando un ambiente de empatía, comprensión y respeto en nuestro entorno.

- Aprendiendo a perdonar a los otros y a uno mismo viviendo el aquí y ahora.

- Dejando de lado el qué dirán y la crítica negativa, y los sentimientos de rencor que son como veneno que nos va destruyendo.

- Pidiendo las caricias que necesitemos, para no tenerlas que buscar de forma negativa.

- Saber autorespetarse.

- Mirarse todos los días al espejo y decirse o darse mensajes agradables.

- Planificar objetivos en la vida y llevarlos a cabo.

- Aceptar y querer nuestro cuerpo como es.

\section{Bibliografía}

Roy, Callista. The Roy Adaptation Model: 3rd (third) Edition. Upper Saddle River, N.J.: Pearson Education. 2009.

Berne, Eric. Más allá de juegos y guiones: Una selección de todas las obras del creador del Análisis Transaccional. Jeder Libros Edit. 2016.

Cibanal Juan, Luis; Arce Sánchez, $\mathrm{M}^{\mathrm{a}}$ del Carmen; Carballal Balsa, $\mathrm{M}^{\mathrm{a}}$ Consuelo. Técnicas de comunicación y relación de ayuda en Ciencias de la Salud. $3^{\text {a }}$ Edit. Ed. Elsevier. 2014.

Egan, Gerard. El laboratorio de relaciones interpersonales. Buenos Aires: Paidós. 1976.

May, Rollo. Amor y voluntad: contra la violencia y la apatía en la sociedad actual ( $3^{\mathrm{a}}$ edit). Gedisa. 2011.

Rogers, Carl. Psicoterapia centrada en el cliente. Buenos Aires: Paidós. 1984.

Verny, Thomas. La vida intrauterina del niño antes de nacer. Ed. Urano. 1988.

Frank, Victor. El hombre en busca de sentido. Ed. Herder. 2005. 